\title{
PV Solar-Optimal Maximum Power Search using a Modified P\&O Technique
}

\author{
Mohamed S. Ebrahim, Adel M. Sharaf, Ahmed M. Atallah, and Adel S. Emarah
}

\begin{abstract}
Smart Grid- PV system interface requires power electronic converter interface and a robust optimal controller to ensure maximum solar energy utilization. This paper presents a new Controller based on an optimized search algorithm for maximum power point tracking controller performance using a modified Perturb and Observe P\&O Algorithm for a smart grid-connected PV DC-AC interface system. The modified $P \& O$ method is based on dividing the change of the power into three distinct zones with assigned zone- duty cycle ratio of the Chopper converter (D) has an initial preset value. The feasibility of the proposed method is easily implemented using proportional plus integral and fuzzy logic controllers. The controllers are assumed to control the active output power through adjusting of the DC bus voltage as well as the reactive power given to the AC smart grid network. Digital simulation results of a comparison with the conventional P\&O approach reflect the fast conversion and dynamic superiority of the new algorithm even under both uniform and partial shading conditions. Furthermore, the active and reactive output powers are regulated at the inverter interface with the smart grid.
\end{abstract}

Index Terms-Maximum Power Point Tracking (MPPT); Perturb and Observe (P\&O); System Configuration; Proposed Algorithm; Active and Reactive Power Control.

\section{INTRODUCTION}

Among the various renewable distributed DG generating systems photovoltaic (PV) array is considered to be a viable and promising renewable power source in the future. The output from any PV power source depends on the weather conditions such as solar radiation and temperature.

Nonlinear characteristics of a PV power curve are a function of irradiance and temperature. For better efficient energy utilization, it is necessary to operate the system at its Maximum Power Operating Condition (MPP). Numerous algorithms have been proposed for Maximum Power Tracking [1],[2]. The Perturb and Observe (P\&O) method is considered the most common method due to its simplicity, and ease implementation [3]. Many types of research investigate the nonlinear behavior of the PV array [2] and associated grid-connected inverters [4]. Despite the simplicity of the classical $\mathrm{P} \& \mathrm{O}$ method, it has two drawbacks. Firstly, once the algorithm reaches the point of maximum power this operating point is forced to go back

Published on May 4, 2017.

M. S. Ebrahim is Senior Electrical and Instrument Engineer at Rashpetco-Shell-JV (e-mail: mohamesalama@ gmail.com).

A. M. Sharaf is Life Senior Member IEEE, Fredericton, NB - Canada (email: profdramsharaf@ yahoo.ca)

A. M. Atallah Professor of Electrical Power, Ain Shams University, Egypt (e-mail: Atallah-g@ENG.ASU.ED.eg).

A. S .Emarah is Professor of Electrical Power, Ain Shams University, Egypt (e-mail: Aemarah4@yahoo.com). and forward. Hence; oscillation appeared around the true MPP. Secondarily, the P\&O always lose its tracking trajectory by changing the environmental conditions.

This work focuses on the modified method to enhance the performance of the traditional $\mathrm{P} \& \mathrm{O}$ and eliminate power tracking oscillatory behavior. The proposed controller utilizes the traditional $\mathrm{P} \& \mathrm{O}$ but with the additional feature of using variable step size rather than fixed step. The performance of the proposed controller is studied under different environmental conditions such as changes in the solar irradiance level, and when the PV is exposed to partial shadow conditions. In general, $\mathrm{P} \& \mathrm{O}$ and its modified version with the variable step or fixed step [5] methods are the simplest. In literature, the general trend in this direction is toward more modifications in the $\mathrm{P} \& \mathrm{O}$ method to retain its aforementioned advantages. In addition $t$ investigating the advantages gained by adding one or more of the new intelligent algorithms to reach the certain level of control quality requirements. PV systems, a grid-connected VSI-inverter converts the DC output voltage of the solar $\mathrm{PV}$-modules into the AC system. An important point related to the photovoltaic system connected to the electric smart grid is the control of active and reactive powers. Control of real \& reactive powers in PV system connected to the grid was achieved through using the PI controller for active power control and fuzzy logic control (FLC) for reactive power control. The control scheme is based on controlling the direct and quadratic components (Id, Iq).

System Configuration

The block diagram of the proposed study DC-AC system is shown in Fig 1.

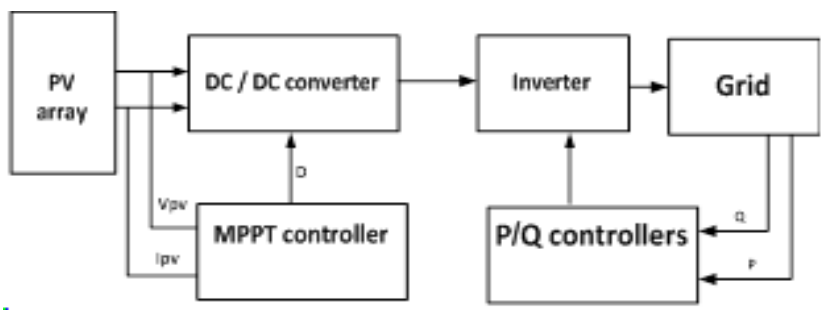

Fig. 1. System Configuration

The system in Fig.1. Consists of energy conversion unit (solar PV system), main control unit (MPPT controller), Boost DC-DC converter and an inverter converting DC power to AC power supplied to load/grid system. The main control unit (MPPT) provides the PWM signal for the boost converter to track the peak power available from PV panel and transfer it to the load/grid [6]. Parameters of PV array according to Table I. The output DC voltage of DC-DC step-up (Boost) converter can be controlled by changing the duty cycle (D) of the transistor switch, which serves as the 
control input. The duty ratio for the converter is decided by the MPPT algorithm. It is assumed that the switching Pulse Width Modulation (PWM) frequency fs is significantly higher than the bandwidth of the control loop. TABLE I: PARAMETERS OF PV ARRAY

\begin{tabular}{lc}
\hline \hline Performance index & Parameter \\
\hline Rated power of each module & $1.1 \mathrm{KW}$ \\
Open circuit voltage (Voc) & $60.2 \mathrm{VDC}$ \\
Short-circuit current (Isc) & $23.25 \mathrm{~A}$ \\
Voltage at MPP (Vmpp) & $58.4 \mathrm{VDC}$ \\
Current at MPP (Impp) & 21.22 \\
No of parallel (Np) & 9 \\
\hline \hline
\end{tabular}

\section{THE PERTURB \&OBSERVE (P\&O) TECHNIQUE}

Convention $\mathrm{P} \& \mathrm{O}$ is widely used in industrial applications where it's easy to be implemented due to its low cost, $\mathrm{P} \& \mathrm{O}$ is divided into many techniques, first is $\mathrm{P} \& \mathrm{O}$ with fixed step, in this method, a fixed perturb value is utilized to generate a reference signal. The perturb signal is either the module reference current or voltage. The fixed perturb step is estimated according to the system designer based on the previous experience. Therefore, the solution from this method is not generic. For small perturb steps, the tracking is slow but the power/voltage oscillations are small. In the case of large perturb step, faster tracking is achieved with increased oscillations. Hence, The $\mathrm{P} \& \mathrm{O}$ method with fixed perturb [7] has an inherent tracking-oscillations. The second method modifies $\mathrm{P} \& \mathrm{O}$ with fixed steps this method is as the previous but instead of utilizing the module current or voltage as the perturbed signal, duty ratio of the converter is used, i.e., direct control of the converter's duty cycle, but the previous problem still persists. The third method used the FLC [8] to estimate the desired step size of the duty cycle in different weather condition, i.e. large step when operating point is far away MPP, and Vic versa, but during large irregular shadow the oscillation appears, then the FLC is required to be modified to adapt the required step size (adaptive techniques). The operation of the conventional $\mathrm{P} \& \mathrm{O}$ in Fig. 2 is based on measuring the value of voltage (V) and current (I) to calculate the power from the PV array according to eq. 1 .

$$
\begin{array}{ll}
\text { IF } \mathrm{P}>\mathrm{P}_{\text {OLD }} & \text { Then } \mathrm{V}_{\text {new }}=\mathrm{V}_{\text {old }}+\Delta \mathrm{V} \text { x slop } \\
\text { IF } \mathrm{P}<\mathrm{P}_{\text {OLD }} \text { Then } \mathrm{V}_{\text {new }}=\mathrm{V}_{\text {old }}-\Delta \mathrm{V} \text { x slop }
\end{array}
$$

Where $\mathrm{P}_{\text {old }}$ is the previous value of power, slop indicates that the direction of the perturbation to right or left based on its signs. (i.e. Incrementing or descending) According to eq. 1 The size of the perturbation $\Delta \mathrm{V}$ is crucial. i.e. if $\Delta \mathrm{V}$ is large the convergence to MPP is fast, but the oscillations in $P$ increased and vice versa, the output power continues to oscillate around the MPP. If $\mathrm{v}(\mathrm{k})$ is increased by a step $\Delta \mathrm{v}(\mathrm{k})$. The power $\mathrm{p}(\mathrm{k})$ will be increased. i.e. $\Delta \mathrm{p}(\mathrm{k}) / \Delta \mathrm{v}(\mathrm{k})>0$, the control causes $\mathrm{v}(\mathrm{k})$ to be $\mathrm{v}(\mathrm{k})+\Delta \mathrm{v}(\mathrm{k})$ (i.e. The operating point is moved forward) toward $\mathrm{p}(\mathrm{k}+1)>\mathrm{P}(\mathrm{k})$ by increasing duty cycle (D) of dc-dc converter. Otherwise $\mathrm{v}(\mathrm{k}+1)=\mathrm{v}(\mathrm{k})$ $\Delta \mathrm{v}(\mathrm{k})$ i.e. $\mathrm{v}(\mathrm{k})$ moves back in the opposite direction. The algorithm continues in the perturbation cycle $(k+1)$ in the same way.

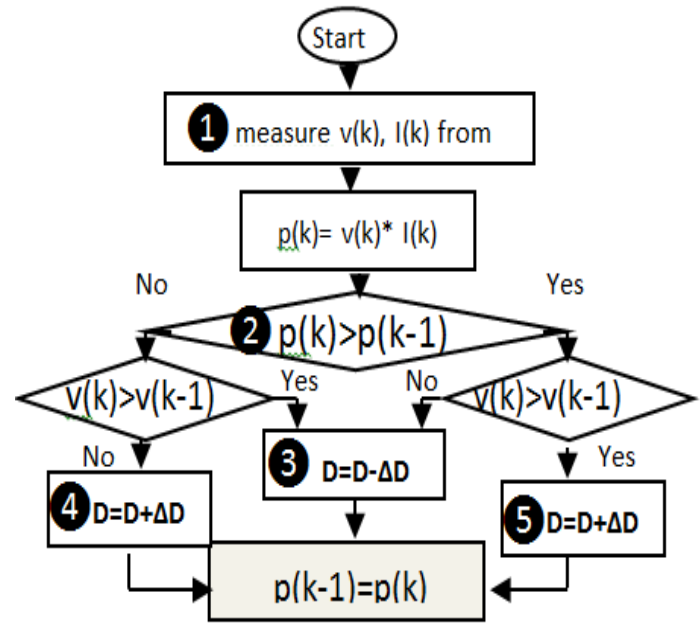

Fig. 2. Flowchart of The Perturb \& Observe (P\&O) Algorithm

\section{FUZZY LOGIC CONTROL (FLC)}

FLC and neural network MPPTs are more rapid, accurate and have improved system performance and regulation [9] FLC system is based on the concepts of approximate reasoning [8], which is applied in process control and regulator design. FLC has two inputs; error E and change of error $\Delta \mathrm{E}$ as shown in Fig. 3. The input for the fuzzy controller is chosen to be $\Delta \mathrm{P} / \Delta \mathrm{V}$ where it represents the $\mathrm{P}-\mathrm{V}$ curve slope, $\Delta \mathrm{P} / \Delta \mathrm{V}$ is an error (E) signal because it is zero at the MPP. $\Delta \mathrm{E}$ is defined as the change of $\Delta \mathrm{P} / \Delta \mathrm{V}$. Under varying irradiation and temperature, FLC achieves better performance than the $\mathrm{P} \& \mathrm{O}$ control method [9]. However, the choice of the rule base table of FLC affects greatly its effectiveness [12].

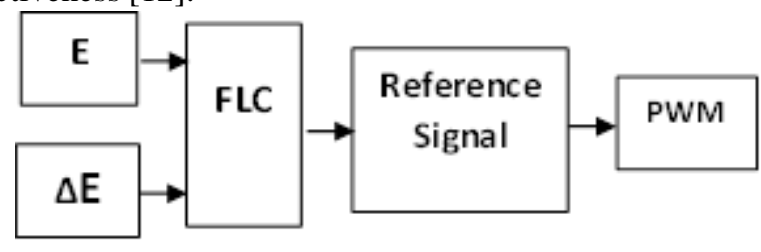

Fig. 3. Fuzzy Logic Control (FLC)

FLC is based on three stages: (1) Fuzzification stage: it converts input variables into linguistic variables based on a Membership function, (2) rule base stage, and (3) Defuzzifcation stage. The behavior of a FLC depends on the shape of membership functions of the rule base. The Gaussian membership function is used. The controller produces an analog output signal, which can be converted to a digital signal and controls the power converter of the MPPT system. Voltage and power are measured to calculate $\mathrm{E}$ and $\Delta \mathrm{E}$. The rule table is designed and shown in Table II.

TABLE II: FLC CONTROL RULES

\begin{tabular}{lccccc}
\hline & & & & & \\
\multicolumn{1}{c}{$\mathrm{NE}$} & $\mathrm{NB}$ & $\mathrm{NS}$ & $\mathrm{Z}$ & $\mathrm{PS}$ & $\mathrm{PB}$ \\
\hline $\mathrm{NB}$ & $\mathrm{PB}$ & $\mathrm{PB}$ & $\mathrm{PS}$ & $\mathrm{PS}$ & $\mathrm{Z}$ \\
$\mathrm{NS}$ & $\mathrm{PB}$ & $\mathrm{PS}$ & $\mathrm{PS}$ & $\mathrm{Z}$ & $\mathrm{PS}$ \\
$\mathrm{Z}$ & $\mathrm{PB}$ & $\mathrm{PS}$ & $\mathrm{Z}$ & $\mathrm{NS}$ & $\mathrm{NB}$ \\
$\mathrm{PS}$ & $\mathrm{NS}$ & $\mathrm{Z}$ & $\mathrm{NS}$ & $\mathrm{NS}$ & $\mathrm{NB}$ \\
$\mathrm{PB}$ & $\mathrm{Z}$ & $\mathrm{NS}$ & $\mathrm{NB}$ & $\mathrm{NS}$ & $\mathrm{NB}$ \\
\hline \hline Z: zero, S: small B: Big, P: positive, $N$ : negative, NB: negative big, $P B$
\end{tabular}

Z: zero, $S$ : small B: Big, $P$ : positive, $N$ : negative, $N B$ : negative big, $P B$ : positive big, etc...... 
According to Table II, both error and change in error are described through using the rules: for example, if the error is $\mathrm{PB}$ (positive big), and change in error is a PS (positive small), then the control signal is PM (positive medium).

The error $(\mathrm{E})$ and change of error $(\Delta \mathrm{E})$ are given by (2) and (3) respectively:

$$
E(k)=\frac{\Delta P}{\Delta V}=\frac{P(k)-P(k-1)}{V(k)-V(k-1)}
$$

$$
\Delta E(k)=E(k)-E(K-1)
$$

\section{PRoposed Algorithm}

The proposed controller is based on the modification of the $\mathrm{P} \& \mathrm{O}$ algorithm through using variable perturbation steps. A three-level perturbation step approach is proposed to $\mathrm{P} \& \mathrm{O}$ method as shown in Fig. 4-a. Inputs for the proposed controller are voltage and current from a PV system. The proposed controller uses the change in Power $(\Delta \mathrm{P})$ to estimate the perturbation steps. In addition, the nonlinearity of the PV characteristic was studied, under changing of weather condition such as partial shadowing. The PV curve was divided into three zones, the MPP achieved when $\mathrm{dP} / \mathrm{dV}=0$, from this condition the proposed controller divided the PV curve into three zones, based on the change of the power. The duty cycle at each zone was updated with the new value. The criterion of the proposed algorithms is generally divided the $\mathrm{P}-\mathrm{V}$ curve into 3 regions, as shown in Fig. 4-b, for a typical P-V curve, the three levels of perturbation step are as follows: $0.75 * \mathrm{D}$ suits region $3 ; 0.25^{*} \mathrm{D}$ suits region 2 and $0.5 * \mathrm{D}$ suits region 1 .

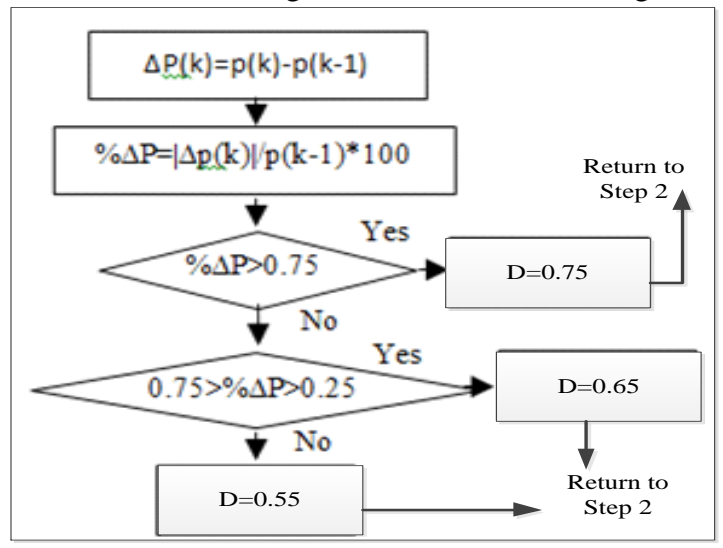

(a)

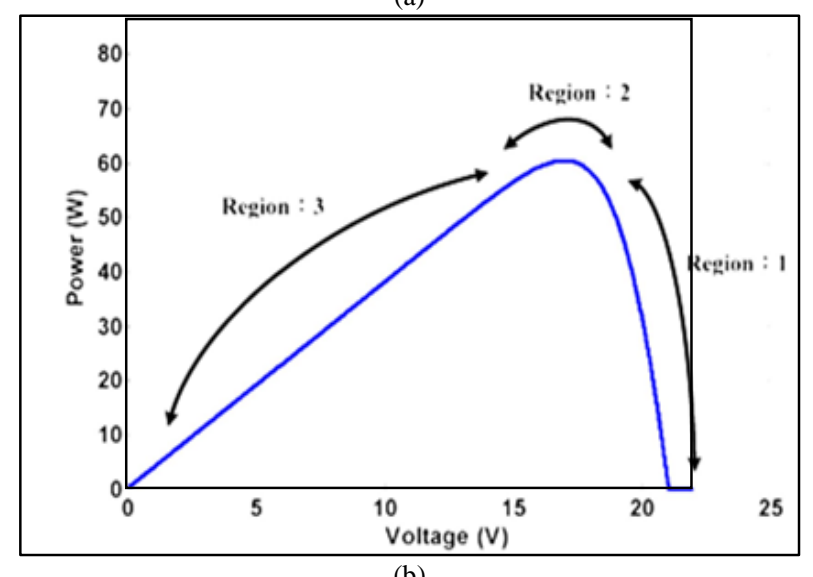

(b)

Fig. 4. (a) Modified Variable Step P\&O algorithm, (b) Operating Regions of PV cell Power-Voltage curve.

\section{MODELING PV ARRAY}

Accurate mathematical model is necessary to represent the electric characteristics of PV module (Appendix A). The conventional equivalent circuit of the solar cell is expressed by one or two diodes whereas representing by a photocurrent source [10, 11], parallel diode, and shunt resistance (Rsh) and series resistance (Rs) as seen in Fig 5. The current source (Ipv) models the sunlight energy conversion; the shunt resistance represents the consequence of leaks, the series resistance represents the various resistances of connections and the diode model the p-n junctions.

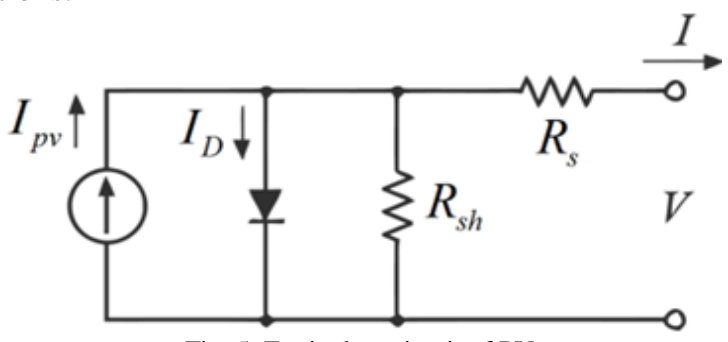

Fig. 5. Equivalent circuit of PV

PV cells are interconnected in series-parallel configuration to form PV modules and arrays [PV generators]. PV array is modeled [12] by (4):

$I_{m}=I_{p h}-I_{d}\left[\exp \left(\frac{q\left(V_{p h}+I_{m} R_{s}\right.}{n K_{T}}\right)-1\right\rceil-\frac{V_{p h}+I_{m} R_{s}}{R_{s h}}$

Where $\mathrm{q}$ is the charge on the electron, $\mathrm{n}$ is the number of cells in series, $\mathrm{k}$ is the Boltzmann constant and $\mathrm{T}$ is the absolute temperature (Kelvin), $\mathrm{I}_{\mathrm{ph}}$ is the photoelectric current, $\mathrm{I}_{\mathrm{m}}$ is the current generated by the PV array.

$$
I_{p h}=I_{s c o}\left(\frac{G}{G_{0}}\right)\left(1+\alpha\left(T-T_{0}\right)\left(\frac{R_{S}+R_{S h}}{R_{s h}}\right)\right.
$$

Where Isco is the short-circuit current of the module at standard irradiation $\mathrm{G}_{0} \quad\left(1000 \mathrm{~W} / \mathrm{m}^{2}\right)$ and standard temperature $\mathrm{T}_{0}\left(25^{\circ} \mathrm{C}\right)$ and $\alpha$ is the module's temperature coefficient. The PV array is modeled using the equations mentioned above. The PV module specifications at standard test conditions are mentioned in Table I the above equations are used through Matlab/SIMULINK to simulate the system shown in Fig. 1, and Fig. 6. Shows the I-V and P-V curves of a PV cell.

\section{Digital Simulation Results}

In order to validate the performance and prove the effectiveness of the proposed controller, a comparison with the conventional $\mathrm{P} \& \mathrm{O}$ controller is examined. The proposed controller and the convention $\mathrm{P} \& \mathrm{O}$ are simulated. Step response of the proposed $\mathrm{P} \& \mathrm{O}$ is simulated. The irradiation level was changed from $1000 \mathrm{~W} / \mathrm{m} 2$ to $700 \mathrm{~W} / \mathrm{m} 2$. Fig. 7a,b show a comparison between conventional $\mathrm{P} \& \mathrm{O}$, and proposed algorithm under changing at radiation level. Results show the modified $\mathrm{P} \& \mathrm{O}$ algorithm and the conventional method are tracking the operating point quickly at the first step of irradiance level, but it's obviously noticed that as long as the irradiance level decrease to 700 $\mathrm{W} / \mathrm{m} 2$ the oscillation level of conventional $\mathrm{P} \& \mathrm{O}$ increased, while the proposed algorithm fast-tracking and convergence 
of the set point as compared with the conventional $\mathrm{P} \& \mathrm{O}$. The performance of the proposed controller is studied under variable changes in the irradiance level, it's considered that the irradiance level changes from $1000 \mathrm{w} / \mathrm{m}^{2}$ to $600 \mathrm{w} / \mathrm{m}^{2}$, then to $400 \mathrm{w} / \mathrm{m}^{2}$, according to Fig. 7-c, from the obtained results the proposed $\mathrm{P} \& \mathrm{O}$ shows a significant improvement in the sudden change in the irradiance levels. Fig. 7-c represents the performance of the controller under a large change in the irradiance level, the performance of the controller is compared with the conventional P\&O. The proposed controller shows the better transient response, and reduction of the oscillation during sudden changes in the weather conditions.

\section{PARTIAL SHADOWING CONDITIONS}

Study of partial shading on PV interconnected modules is considered to be a key issue with the performance of a PV scheme, The performance has adversely affected if all cells are not equal irradiated. Different patterns of shadows are applied on the PV modules according to the irradiance profile as shown in Fig. 8-a. To determine the effects of various its power output. In To determine the effects of various power output; digital simulations have been carried out. The previous mention MPPT controllers are used for ensuring the validation and the effectiveness of these controllers to track MPP under a partial shadow. The PV array is subjected to the irradiance level according to Fig. 8aThe obtained results from these controllers achieved better tracking of MPP when the irradiance level is kept constant. Fig. 8-b shows the results of the proposed controller under partial shadowing, better tracking and stability were achieved as compared with conventional P\&O.
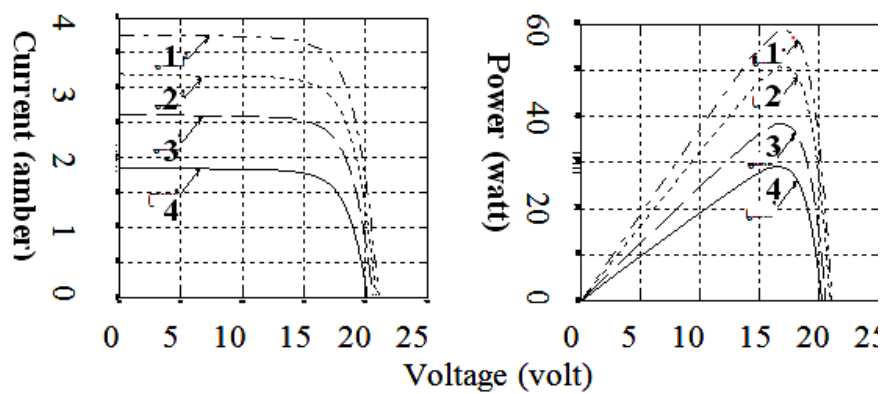

$1: 1000 \mathrm{w} / \mathrm{m}^{2}$

\section{3:650 w/m $/ \mathrm{m}^{2} \quad 4: 500 \mathrm{w} / \mathrm{m}^{2}$}

Fig. 6. PV cell Current-Voltage \&Power-Voltage curve.

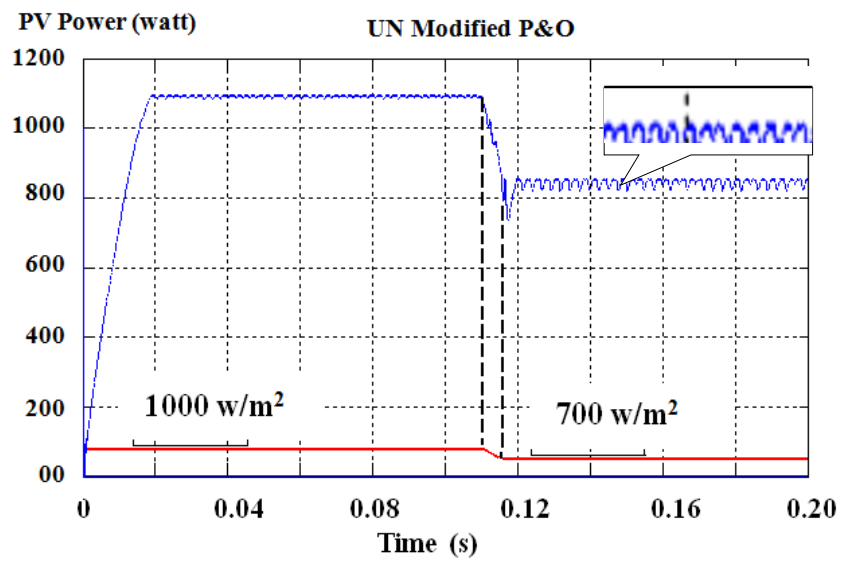

(a)

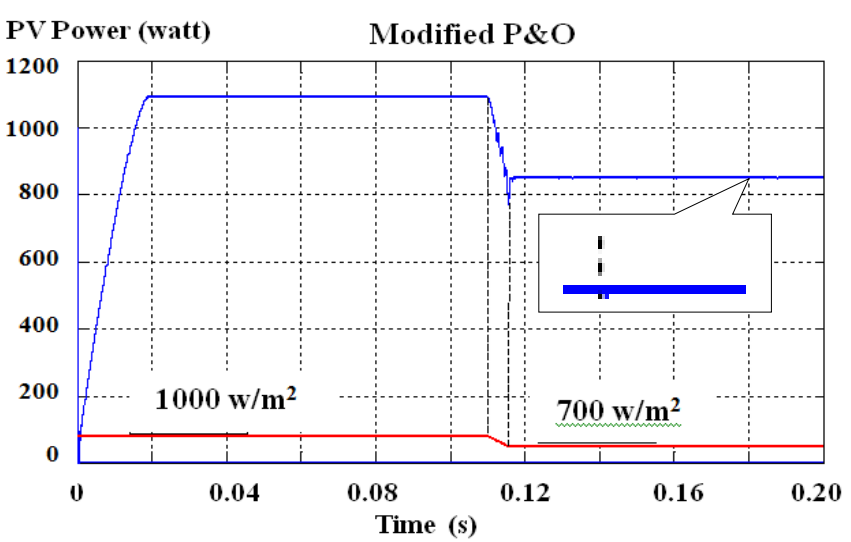

(b)

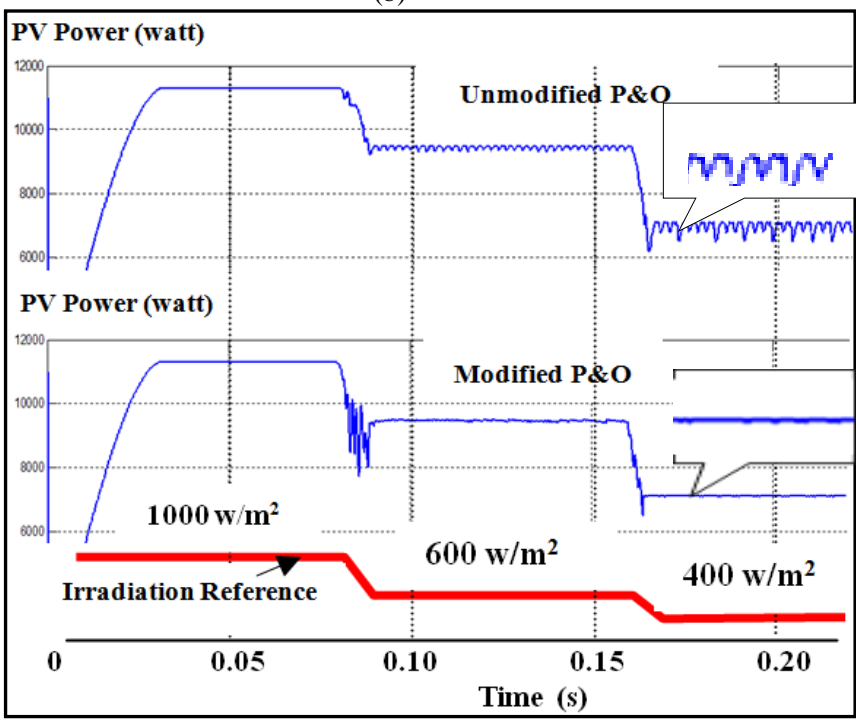

(c)

Fig. 7. (a) Dynamic time response of P\&O MPPT Controller. (b) Dynamic time response of the Modified P\&O MPPT Controller. (c) Dynamic Time Response of Modified P\&O MPPT.

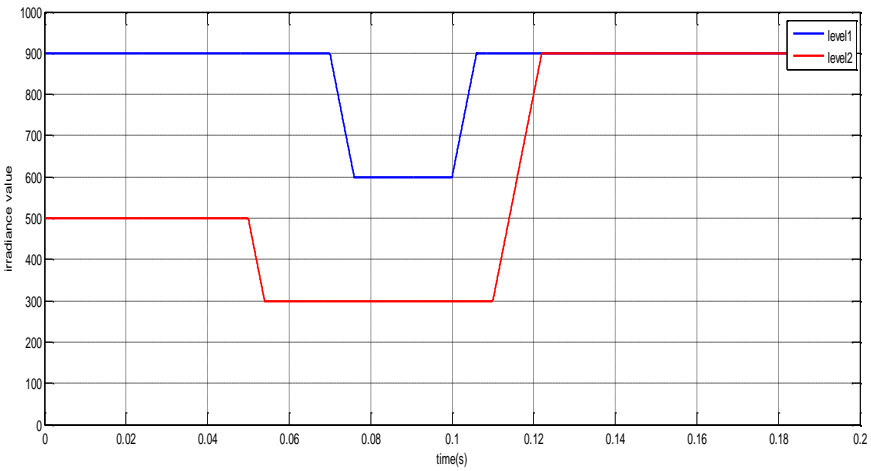

(a)

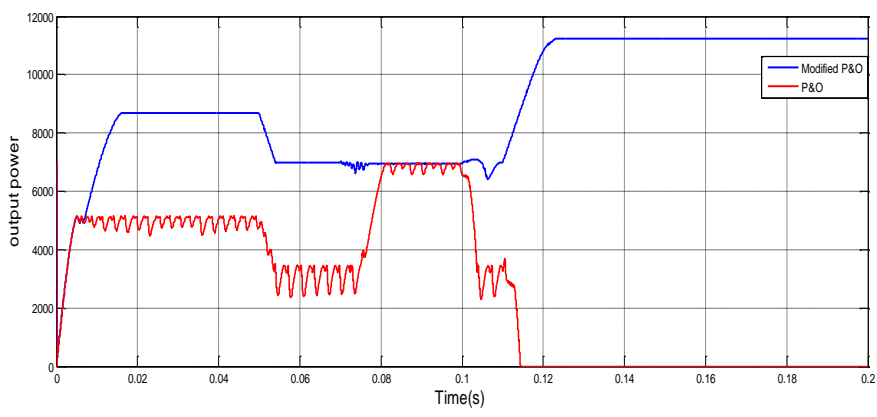

(b)

Fig. 8. (a) Irradiance level. (b) Output power under a partial shadow from both controllers. 
Also, there are many algorithms used for MPPT tracking under varying insolation/irradiation level [16],[17] such as $\mathrm{P} \& \mathrm{O}$ with PI controller, fuzzy logic controller (FLC), and FLC with PI controller. The obtained results from these controllers achieved better tracking of MPP when the irradiance level is kept constant. Fig. 9-a represents the performance test under the step change of the irradiance level, most of all methods achieve better tracking, however, the oscillations are persisted. Fig. 9-b shows the results of the previous mention algorithms under the partial shadow, the PV array is subjected to the irradiance level according to the Fig. 9-c. The obtained result shows that the effect of using FLC with PI controller is better than using FLC and P\&O with PI, but still away from MPP.

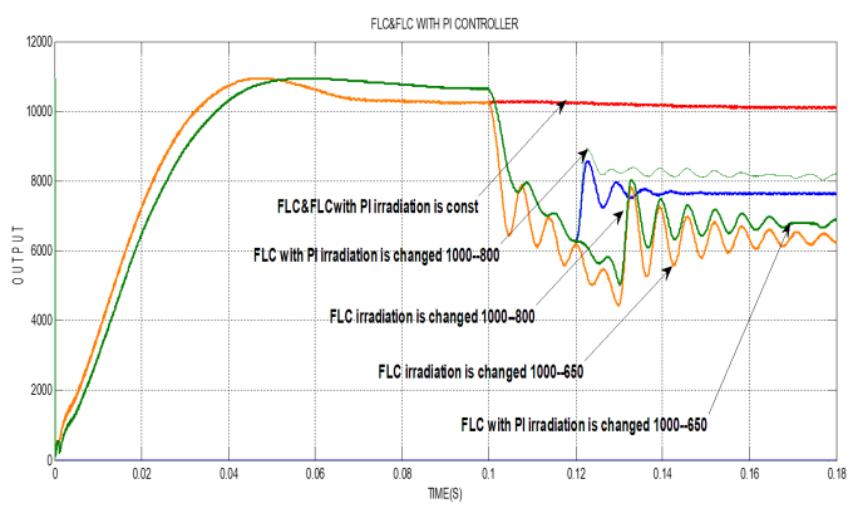

(a)

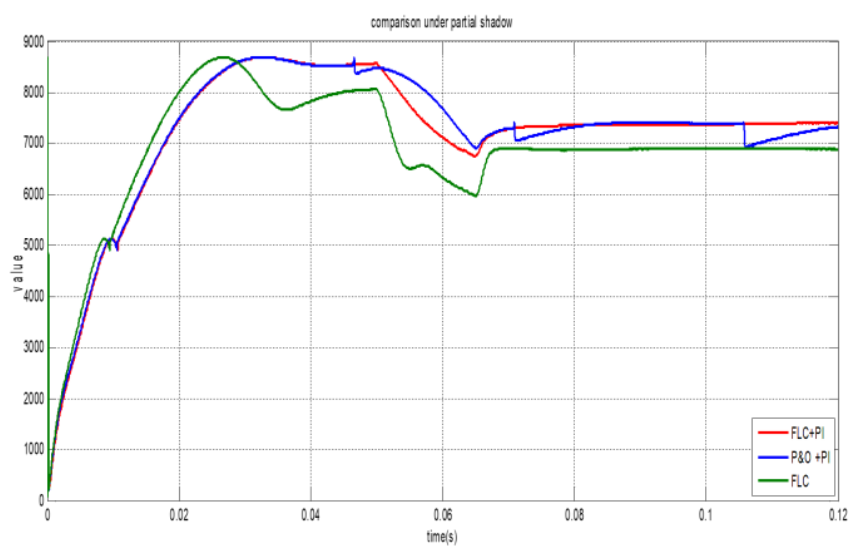

(b)

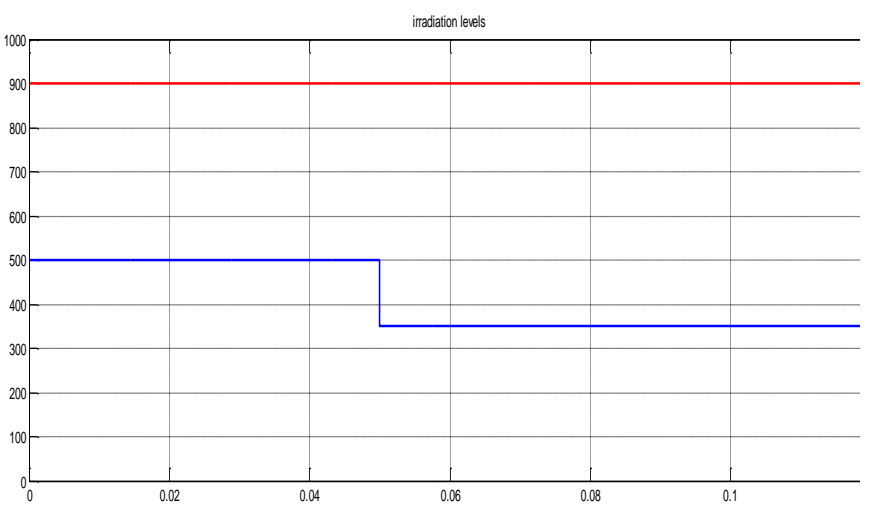

(c)

Fig. 9. (a) Results from FLC\&FLC with PI controller under changes in irradiance. (b) Results under a partial shadow. (c) Irradiance profile

\section{INVERTER-ACTIVE AND REACTIVE POWER CONTROL}

Basically, the control algorithm of the smart grid inverter PV system has the main functions [19] Control the real power and regulate the reactive power into the grid, and ensure the stability of the DC bus voltage. The inverter control is based on a decoupled control of the active and reactive power. The output power $\mathrm{P}$ from the inverter is set by a proportional-integral controller (PI) and provides $\mathrm{Id}^{*}$ active direct current reference in a synchronous reference frame. The second component of the current vector represents the reactive current Iq*. FLC is used to control the reactive power (Appendix B contains Fuzzy gains) Applying the inverse Park transformation to $d-q$ frame current vector components, the desired Id_ref \&Iq_ref abc phase current references are obtained. Active and reactive power of the PV system connected to the grid can be controlled simultaneously and independently [19]. Fig.10-a, represents the control algorithm that used to control the VSC. This algorithm used to synchronize with grid [19]. Also, control both real and reactive power. The control objective of the reactive power is to maintain the system voltage at a certain value or reference value, this can be implemented through control the Q component of (Iq), also control the real power through regulating the DC bus voltage to control the D component of (Id). Fig. 10-b represents the control scheme that is used to control the active/reactive power, the PI controller (Appendix C contains PID gains) is used to control the real power through regulate the DC bus voltage then controlled the amount of the power that flows from the inverter, also the Fuzzy controller is used to control the reactive power that will be injected from the inverter to the grid through comparison of the feedback of reactive power ( $Q$ measure), with the reference value ( $Q$ ref).

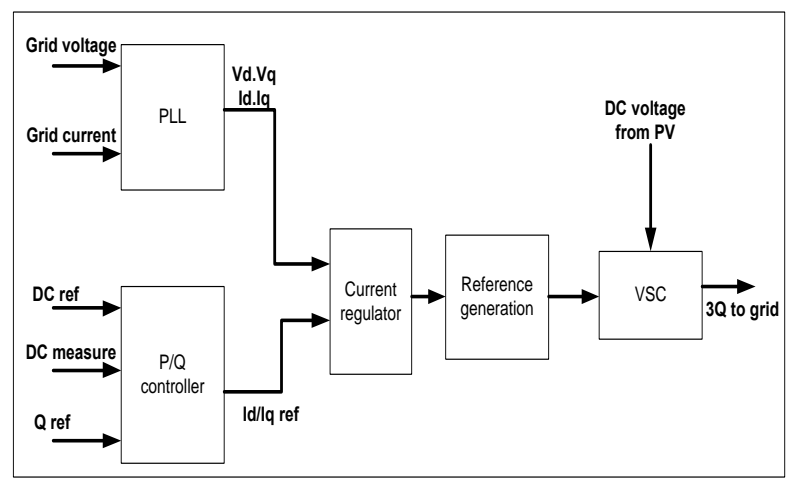

(a)

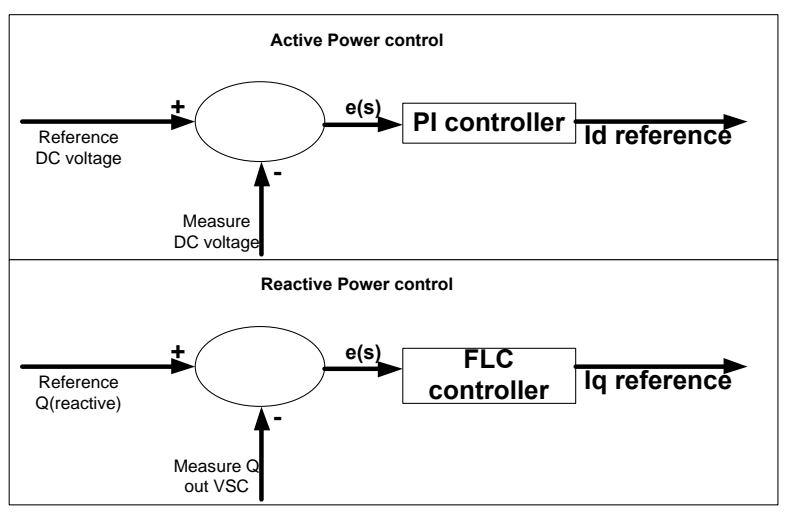

(b)

Fig. 10. (a) Control scheme of PV-smart grid scheme. (b) Active/Reactive controllers 


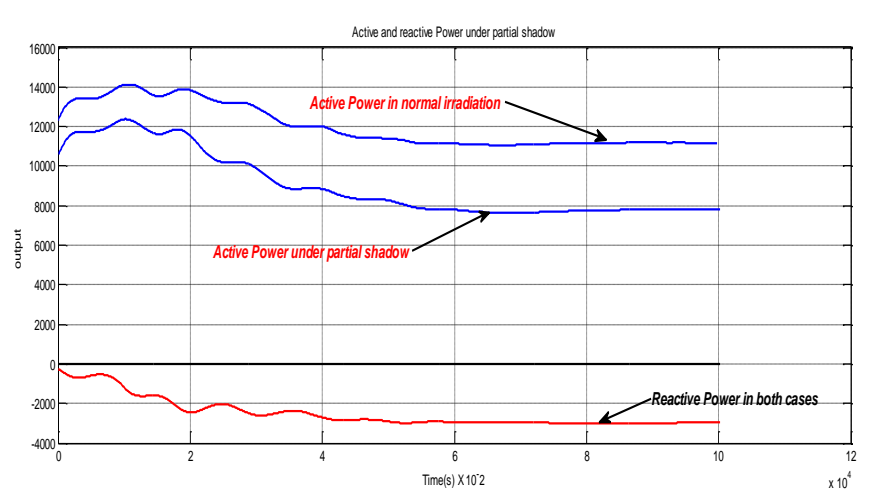

(a)

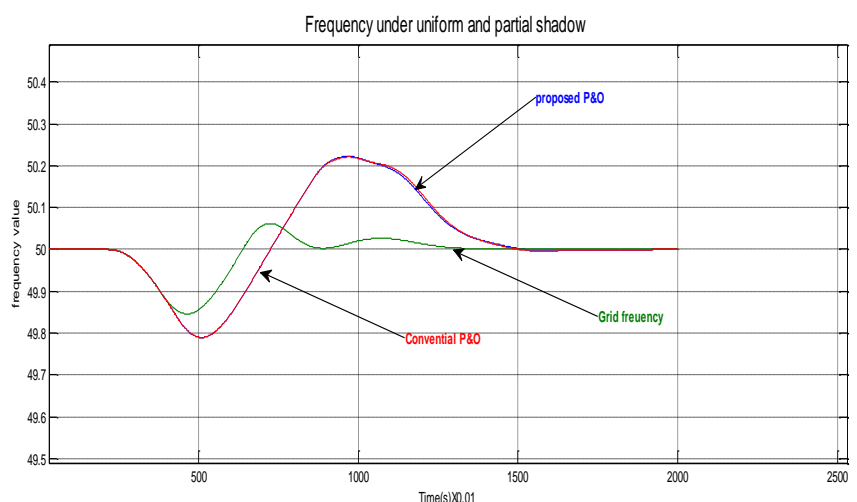

(b)

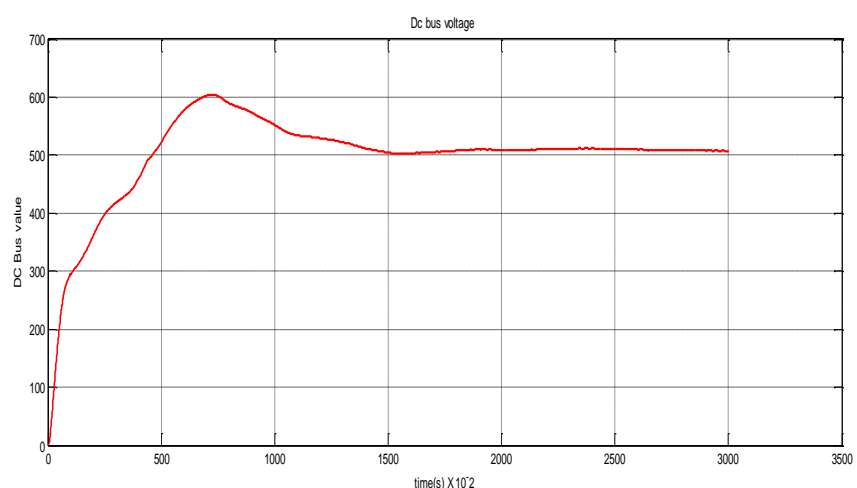

(c)

Fig. 11. (a) Active/Reactive in normal irradiance \& partial shadow. (b) Grid /inverter frequency under partial shadow. (c) DC bus voltage

The performance of the control scheme was studied under the partial shadow, Fig. 11-a, represents the Simulations result of both active and reactive power. From the results, its noticed the effectiveness of using PI to control the active power under changing in the weather condition and the FLC to keep the reactive power within its desired level. In addition, Fig. 11-b represents the grid frequency with inverter's frequency and Fig 11-c represents the DC bus voltage when the irradiance level is changed.

\section{CONCLUSION}

This paper presents a new modified MPPT controller based on a successive dynamic modification of classical $\mathrm{P} \& \mathrm{O}$ algorithm using variable perturbation steps. A three-level perturbation step algorithm is proposed as an addition to P\&O method. Simulation results of the proposed method validated tracking improvement in dynamic solar maximum power performance with reduced oscillatory behavior, the proposed algorithm was compared with the traditional $\mathrm{P} \& \mathrm{O}$ lalgorithm under different conditions such as changing in insolation/irradiation level and partial shadow, for all the tests the proposed controller proved better performance through tracking MPP and less oscillations, also PV system connected to grid, real \&reactive power control are controlled through using PI controller for active power control and FLC to reactive control, the control scheme based on controlling the direct and quadratic components (Id, Iq) . Dynamic simulation results of the three-phase gridconnected PV system during uniform irradiance and partial shadow confirmed that the fast convergence of MPPT and provided the appropriate active and reactive power to the grid. The modified scheme can be extended to the hybrid microgrid using PV-Wind and Battery Storage, Fuel Cell Backup systems.

\section{APPENDIX}

\begin{tabular}{lc} 
A. $P$ V parameters & \\
\hline \hline Performance index & Parameter \\
\hline R1:Resistance & $0.005 \Omega$ \\
L1: inductance & $5 \mathrm{e}-3 \mathrm{H}$ \\
C1: capacitance & $100 \mathrm{e}-6 \mathrm{~F}$ \\
C5 & $12000 \mathrm{e}-06 \mathrm{~F}$ \\
DC bus Voltage & $500 \mathrm{VDC}$ \\
\hline \hline
\end{tabular}

\section{B. Controller parameters}

\begin{tabular}{lc}
\hline \hline Parameters for FLC & value \\
\hline Error gain $\mathrm{E}(\mathrm{k})$ & 0.22 \\
Change of error $\Delta \mathrm{E}$ & 0.1 \\
Control signal $\mathrm{D}(\mathrm{u})$ & .86 \\
Parameters for PI(Discrete) & Value \\
\hline Proportional value Kp & 4 \\
Integral term value $\mathrm{K}(\mathrm{i})$ & 150 \\
\hline \hline
\end{tabular}

\section{REFERENCES}

[1] Liqun Liu,\& XiaoliMeng "A review of maximum power point tracking methods of PV power system at uniform and partial shading " Elsevier Renewable and Sustainable Energy Reviews 53(2016)1500-1507.

[2] T. Esram and P. L.Chapman, "Comparison of photovoltaic array maximum power point tracking techniques, " IEEE Trans. Energy Conv., vol. 22,no. 2, pp. 439-449, Jun. 2007.

[3] Moacyr Aureliano, and Leonardo Poltronieri Sampaio, , "Evaluation of the Main MPPT Techniques for Photovoltaic Applications" IEEE Transaction on industrial Electronics, Vol. 60, NO. 3, March 2013.

[4] S. Jain and V. Agarwal, "Comparison of the performance of maximum power point tracking schemes applied to single-stage gridconnected photovoltaic systems," IET Electr. Power Appl., vol. 1, no. 5, pp. 753-762, Sep. 2007.

[5] Abdelghani Harrag and Sabir Messalti; Variable step size modified P\&O MPPT algorithm using GA-based hybrid offline/online PID controller, ELSEVIER Renewable and Sustainable Energy Reviews 49(2015)1247-1260

[6] S. Jain and V. Agarwal, "A single-stage grid-connected inverter topology for solar PV systems with maximum power point tracking," IEEE Trans. Power Electron., vol. 22, no. 5, pp. 1928-1940, Sep 2007.

[7] Jubaer Ahmed, Zainal Salam; An improved perturb and observe (P\&O) maximum power point tracking (MPPT) algorithm for higher efficiency, ELSEVIER Applied Energy 150 (2015) 97-108.

[8] I.H. Altas and A.M. Sharaf, "A novel GUI modeled fuzzy logic Controller for a solar powered energy utilization scheme", The 13th International Conference on Emerging Nuclear Energy Systems (ICENES2007), June 3-8, 2007, Istanbul, Turkey.

[9] M. G. Villalva, J. R. Gazoli, and E. R.Filho,"Comprehensive approach to modeling and simulation of photovoltaic arrays, " IEEE Trans. Power Electron., vol. 24, no. 5, pp. 1198-1208, May 2009.

[10] Tsai, H.L., C.S. Tu, and Y.J. Su. "Development of generalized photovoltaic model using MATLAB/SIMULINK". in Proceedings of the World Congress on Engineering and Computer Science. 2008. system: A review. Renew. Sustain. Energy Rev. 2013, 19, 433-443. [Google Scholar]. 
[11] I.H. Altas and A.M. Sharaf, "A photovoltaic array simulation model for Matlab-Simulink GUI environment", International Conference on Clean Electrical Power, ICCEP'07, May 21-23, 2007, Capri, Italy.

[12] Tianpei Zhou \& Wei Sun, " Study on maximum power point tracking of photovoltaic array in irregular shadow "Elsevier Electrical Power and Energy Systems 66 (2015) 227-234.

[13] Ali Chermitti,Omar Boukli-Hacene, and Bencherif Mohamed " Improvement of the Perturb and Observe MPPT Algorithm in a Photovoltaic System under Rapidly Changing Climatic Conditions " International Journal of Computer Applications (0975 - 8887) Volume 56- No.12, October 2012.

[14] Ishaque, K.; Salam, Z. A review of maximum power point tracking techniques of PV system for uniform insolation and partial shading condition. Renew. Sustain. Energy Rev. 2013, 19, 475-488.

[15] Reisi, A.R.; Moradi, M.H.; Jamasb, S. Classification and comparison of maximum power point tracking techniques for photovoltaic system: A review. Renew. Sustain. Energy Rev. 2013, 19, 433-443.

[16] Tracking Techniques for Photovoltaic Power Systems " IEEE Transaction on sustainable energy, Vol. 4, NO. 1, JANUARY 2013.

[17] A. M. Sharaf,\& I. H. Altas, " A Novel Multi-Loop PID Controller for Photovoltaic-Grid Interface DC Energy Utilization Farm " International Conference on Renewable Energies and Power,2009.

[18] S. Jain and V. Agarwal, "A single-stage grid connected inverter topology for solar PV systems with maximum power point tracking," IEEE Trans. Power Electron., vol. 22, no. 5, pp. 1928-1940, Sep. 2007.

[19] S. Jain and V. Agarwal, "A single-stage grid connected inverter topology for solar PV systems with maximum power point tracking," IEEE Trans. Power Electron., vol. 22, no. 5, pp. 1928-1940, Sep. 2007.

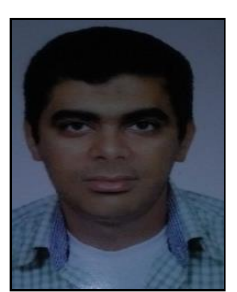

Mohamed S. Ebrahim is an electrical and instrument control engineer in oil\& gas plant. Currently a turbo machinery section head, at Rashpetco-shell, gas plant. received his B.Sc., M.Sc. and ongoing to finalize Ph.D. His current research areas include renewable energy, and artificial intelligent applications.

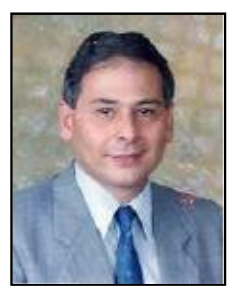

Prof. Adel M. Sharaf obtained his B.Sc. degree in Electrical Engineering from Cairo University in 1971. M.Sc degree in Electrical engineering in 1976 and $\mathrm{Ph} . \mathrm{D}$ degree in 1979 University of Manitoba, Canada and was employed by Manitoba Hydro as Special Studies Engineer, responsible for engineering and economic feasibility studies in Electrical Distribution System Planning and Expansion. He was selected as NSERC-Canada research-assistant professor in 1980 at University of Manitoba. He joined the University of New Brunswick in 1981 to start a tenure-track academic career as an Assistant professor and he was promoted to Associate Professor in 1983, awarded tenure in 1986, and the full professorship in 1987. He has extensive industrial and consulting experience with Electric Utilities in Canada and Abroad.

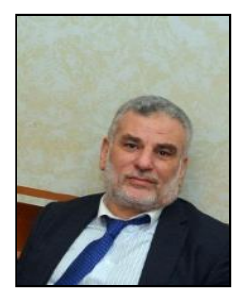

Prof. Ahmed M. Atallah B.Sc. and M.Sc. from Electrical Power and Machine Dept., Faculty of Eng., Ain Shams Univ., Cairo, Egypt. 1979 and 1984. $\mathrm{PhD}$. from electrical Eng. Dept., Faculty of Eng., Univ. of Alberta, Edmonton, Alberta, Canada1988. Interested in renewable energies.

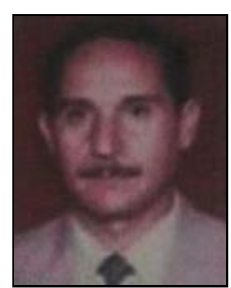

Prof. Adel Sedky Emarah B.Sc. and M.Sc. from Electrical Power and Machine Dept., Faculty of Eng. Ain Shams Univ. Cairo, Egypt. PhD. from electrical Eng. Dept 1972 and 1977 from USA. Interested in renewable energies. 